\title{
Influence of Combustion Initial Conditions on Emissions Production Rates and Released Heat for Methane Fuel Mixtures
}

\author{
Ali S. Al-Shahrani \\ Department of Mechanical Engineering, Jazan University, Jazan, KSA \\ Email: aalshahrany@jazanu.edu.sa
}

How to cite this paper: Al-Shahrani, A.S. (2017) Influence of Combustion Initial Conditions on Emissions Production Rates and Released Heat for Methane Fuel Mixtures. World Journal of Engineering and Technology, 5, 333-339.

https://doi.org/10.4236/wjet.2017.52027

Received: May 3, 2017

Accepted: May 24, 2107

Published: May 27, 2017

Copyright $\odot 2017$ by author and Scientific Research Publishing Inc. This work is licensed under the Creative Commons Attribution International License (CC BY 4.0).

http://creativecommons.org/licenses/by/4.0/

\begin{abstract}
An estimation of combustion products (pollutants) which include $\mathrm{CO}, \mathrm{CO}_{2}$ and NO mole fraction are reported in this paper for premixed methane/air flames. Different mixtures were used in this study, including lean, stoichiometric and rich subjected to varying degrees of pressures and temperatures ranging from 5 - 40 bars and $350-600 \mathrm{~K}$, respectively. In this work, computer software was used to calculate the produced emissions species as well as the final (adiabatic) temperatures for each mixture. Results show that rich mixture of methane fuel produces the highest rate for carbon monoxide (CO) with slight increase as pressure and temperature increase. Where the stoichiometric mixture produces the highest rate of carbon dioxide $\left(\mathrm{CO}_{2}\right)$. Results showed that this type of emission decreases with the increase of pressure and temperature. On the other hand, nitric acid (NO) was found to be the highest for the lean mixture with sharp increase as pressure and temperature increase. Finally, the combustion heat $(Q)$ for each mixture where plotted against pressure and it was found that the rich mixture of methane produced the highest rates. Results also showed that combustion heat increases sharply with increased pressures and temperatures.
\end{abstract}

\section{Keywords}

Hydrocarbon Fuel, Flames, Emissions, Combustion, Carbon Oxides, Nitric Acid

\section{Introduction}

Atmospheric pollution has become a worldwide concern. This concern led to the consideration to the effects of injecting large amounts of any species on the ozone balance in the atmosphere. Combustion processes are typically considered as one of the main responsible parties of the emission to the atmosphere of im- 
portant pollutants. It then became evident that the major species that would affect the ozone balance were the oxides of nitrogen $\mathrm{NO}_{x}$ as well as carbon oxides $\left(\mathrm{CO}_{\mathrm{x}}\right)$ [1] [2]. One major source of such pollutants is automobile exhausts which use fossil fuels (hydrocarbons) in their combustion systems to produce energy [3] [4]. So great interest remains in predicting and reducing these emissions. The aim of combustion devices of engines is to produce high temperatures for heat or power generation whilst producing the least pollutant emissions under controllable conditions. Lean premixed combustion succeeds largely in the first count, whilst coming up short regarding the range of operable conditions. In internal combustion engines, lean combustion provides high efficiencies (due to the high specific heat ratio of air) and low emissions (due to low temperatures), but poor stability. In spark ignition engines, limits to stability can be overcome by injecting additional fuel in strategic locations near the spark plug with penalties associated with the production of $\mathrm{NO}_{\mathrm{x}}$ and particulate matter. In gas turbines and other continuous flow devices, stability is often achieved by providing a richer pilot zone, again at the expense of higher emissions. In other cases, even though premixed conditions are the aim, limited time for evaporation and mixing creates non-uniformities short in fuel concentrations. In all of these situations, the final mixture will react under conditions where there is a range of equivalence ratios or mixture fractions over which the reaction will take place [5]. It then becomes an essential issue to conduct researches which might help to understand the nature of such emissions, and more importantly, the effective ways of minimizing its formation rates [6] [7]. This was done via using in-house computer model at different pressures and temperatures. This in-house software is a chemical equilibrium program, primarily for gas phase combustion. It calculates chemical equilibrium and composition of the flame. By setting the initial conditions, temperature, $T_{u}$ pressure, $P_{u}$, and equivalence ratio, $\phi$, for the chosen hydrocarbon fuel (Methane, $\mathrm{CH}_{4}$ ). Also, for each combustion process, the thermodynamic state type must be defined before running calculations. In this study the process was set at an adiabatic temperature and composition at a constant volume, (as in engines). The software then calculates the adiabatic temperature at equilibrium, $T_{a d}$. Then it calculates the moles fraction of burnt gases (species of interest, $\mathrm{CO}, \mathrm{CO}_{2}, \mathrm{NO}$, emissions) and heat of combustion $(Q \mathrm{~kJ} / \mathrm{kg})$ produced from chemical reaction.

\section{Methods of Prediction Emissions from Burned Methane Fuel}

Levels of emissions of oxides of nitrogen (nitric oxide, $\mathrm{NO}$ and nitrogen dioxide, $\mathrm{NO}_{2}$, usually grouped as $\mathrm{NO}_{x}$ ), where carbon oxides (carbon monoxide, $\mathrm{CO}$ and carbon dioxide, $\mathrm{CO}_{2}$, usually grouped as $\mathrm{Co}_{x}$ ). One way of predicting level of concentrations of such emissions is using Emission Index (EI), which can be found using the following equation [8]:

$$
E I_{\mathrm{NO}_{x}}=\frac{\dot{m}_{\mathrm{NO}_{x}}(\mathrm{~g} / \mathrm{s})}{\dot{m}_{f}(\mathrm{~kg} / \mathrm{s})}
$$


with similar expression for $\mathrm{Co}_{x}$ and others emissions ( $\mathrm{HC}$ and particulates). In this equation emission rates were normalized by the fuel $\left(\mathrm{CH}_{4}\right)$ flow rate. Another approach that can be used in evaluating the concentrations of emissions is by calculating "mole fraction" percentage of the species of interest. In this approach, the most important considerations when predicting $\mathrm{NO}_{x}$ and $\mathrm{CO}_{x}$ emissions are specifying the initial conditions of the combustion process at specified equivalence ratio, $\phi$, for a particular burned fuel. These conditions include pressures and temperatures initial values at each calculation process. Also, type of thermodynamic process must be specified. In this work, the process was chosen to be "adiabatic temperature and composition at constant volume" which is identical to those in internal combustion engines [7] [8] [9]. The chemical reactions approach which lead to formation of such emissions is beyond the scope of this work, more details can be found in [10].

An in-house Software program was used to calculate the adiabatic temperature and equilibrium composition of a flame under certain pressures and temperatures shown below in Tables 1-3. Different types of calculations can be performed by this software. These includes: Equilibrium at defined temperature and pressure. Adiabatic temperature and composition at defined pressure. Equilibrium at defined temperature and constant volume. Adiabatic temperature and composition at constant volume. The software is also capable of handling a group of reactants as a mixture with changing the stoichiometry of a flame burning with air for particular fuel. Three different of Methane-air mixtures with different equivalence ratios $(0.8,1.0,1.2)$ were chosen to study effects of fuel composition. The used model is beyond the scope of this paper, more information can be found in [5]. This program requires input parameters in order to run the calculations. These parameters include initial temperature and pressure $\left(T_{u}, P_{u}\right)$, Equivalence ratio $\phi(0.8,1.0$ and 1.2$)$, and the thermodynamic process at which these calculations will be run at. For this work it was chosen to be an "adiabatic temperature and composition at constant volume" which is identical to those processes in vehicles engines. One the hand, heat of combustion, $\mathrm{Q}(\mathrm{kJ} / \mathrm{kg})$, in each run was also calculated for each condition shown in the mentioned tables.

Table 1. Emissions for lean Methane flames at different initial pressures and temperatures.

\begin{tabular}{cccccccc}
\hline $\begin{array}{c}\text { Combustible } \\
\text { material }\end{array}$ & $\mathrm{Pu}(\mathrm{bar})$ & $\mathrm{Tu}(\mathrm{k})$ & $\mathrm{CO} \%$ & $\mathrm{CO}_{2} \%$ & $\mathrm{NO} \%$ & $\mathrm{Q}(\mathrm{kJ} / \mathrm{kg})$ & $\mathrm{Tad}(\mathrm{k})$ \\
\hline 5 & 350 & 0.168 & 7.564 & 0.823 & 2272 & 2426 \\
& 15 & 400 & 0.129 & 7.606 & 0.878 & 2311 & 2465 \\
$\begin{array}{c}\text { Methane } \\
\left(\mathrm{CH}_{4}\right), \phi=0.8\end{array}$ & 25 & 500 & 0.153 & 7.58 & 0.97 & 2390 & 2526 \\
& 30 & 550 & 0.17 & 7.561 & 1.017 & 2431 & 2557 \\
& 35 & 600 & 0.191 & 7.539 & 1.066 & 2471 & 2587 \\
& 40 & 650 & 0.214 & 7.513 & 1.116 & 2513 & 2618 \\
\hline
\end{tabular}


Table 2. Emissions for stoic Methane flames at different initial pressures and temperatures.

\begin{tabular}{|c|c|c|c|c|c|c|c|}
\hline Combustible material & $\mathrm{Pu}$ (bar) & $\mathrm{Tu}(\mathrm{k})$ & $\mathrm{CO}$ & $\mathrm{CO}_{2}$ & NO & $\mathrm{Q}(\mathrm{kJ} / \mathrm{kg})$ & $\operatorname{Tad}(\mathrm{k})$ \\
\hline \multirow{7}{*}{$\begin{array}{c}\text { Methane } \\
\left(\mathrm{CH}_{4}\right), \phi=1.0\end{array}$} & 5 & 350 & 1.408 & 7.986 & 0.491 & 2796 & 2665 \\
\hline & 15 & 400 & 1.246 & 8.163 & 0.486 & 2832 & 2721 \\
\hline & 20 & 450 & 1.278 & 8.128 & 0.509 & 2869 & 2750 \\
\hline & 25 & 500 & 1.324 & 8.079 & 0.535 & 2906 & 2777 \\
\hline & 30 & 550 & 1.379 & 8.019 & 0.564 & 2944 & 2803 \\
\hline & 35 & 600 & 1.441 & 7.953 & 0.594 & 2982 & 2829 \\
\hline & 40 & 650 & 1.509 & 7.88 & 0.627 & 3020 & 2855 \\
\hline
\end{tabular}

Table 3. Emissions for rich Methane flames at different initial pressures and temperatures.

\begin{tabular}{|c|c|c|c|c|c|c|c|}
\hline Combustible material & $\mathrm{Pu}$ (bar) & $\mathrm{Tu}(\mathrm{k})$ & $\mathrm{CO}$ & $\mathrm{CO}_{2}$ & NO & $\mathrm{Q}(\mathrm{kJ} / \mathrm{kg})$ & $\operatorname{Tad}(\mathrm{k})$ \\
\hline \multirow{7}{*}{$\begin{array}{c}\text { Methane } \\
\left(\mathrm{CH}_{4}\right), \phi=1.2\end{array}$} & 5 & 350 & 4.879 & 5.887 & 0.491 & 3309 & 2612 \\
\hline & 15 & 400 & 4.876 & 5.896 & 0.486 & 3342 & 2652 \\
\hline & 20 & 450 & 4.896 & 5.875 & 0.509 & 3376 & 2684 \\
\hline & 25 & 500 & 4.917 & 5.852 & 0.535 & 2411 & 2715 \\
\hline & 30 & 550 & 4.941 & 5.827 & 0.564 & 3445 & 2746 \\
\hline & 35 & 600 & 4.966 & 5.799 & 0.594 & 3481 & 2777 \\
\hline & 40 & 650 & 4.993 & 5.77 & 0.627 & 3516 & 2808 \\
\hline
\end{tabular}

\section{Results and Discussion}

Three different air-fuel mixtures have been used for methane fuel (CH4), to evaluate the amount of emissions produced in mole fraction for each combustion process. First mixture was lean, $(\phi=0.8)$. Second one was stoichiometry, $(\phi$ $=1.0)$, and the third mixture was rich, $(\phi=1.2)$. Emissions species were, Nitrogen Oxide (NO), Carbon monoxide (CO) and Carbon dioxide $\left(\mathrm{CO}_{2}\right)$. Numerical calculated results for all three emissions are shown in Tables 1-3 at different pressures and temperatures ranging from 5 - 40 bars and $350-600 \mathrm{~K}$, respectively. These results are also plotted in Figures 1-4, pressure versus mole fractions for all species. Results showed that rich mixtures of methane produced the highest values of $\mathrm{CO}$ emissions for rich mixtures $(\phi=1.2)$, where lean mixtures ( $\phi=0.8)$ produced the least values of $\mathrm{CO}$ emissions. This is shown in Fig. 1 for all pressures and temperatures.

On the other hand, $\mathrm{CO}_{2}$ emissions were noticed to be maximum values for stoichiometry $(\phi=1.0)$ mixtures and minimum values for rich mixtures $(\phi=$ 1.2). This is shown in Figure 2. Results also showed that $\mathrm{CO}_{2}$ values shortly increased but then decreased as pressures and temperatures values increased for the stoichiometry $(\phi=1.0)$ mixtures. As shown in Figure 3, NO emissions produced by methane flames. It was found that the highest values were for the lean mixtures $(\phi=0.8)$, and the least ones were for rich mixtures $(\phi=1.2)$. Results 


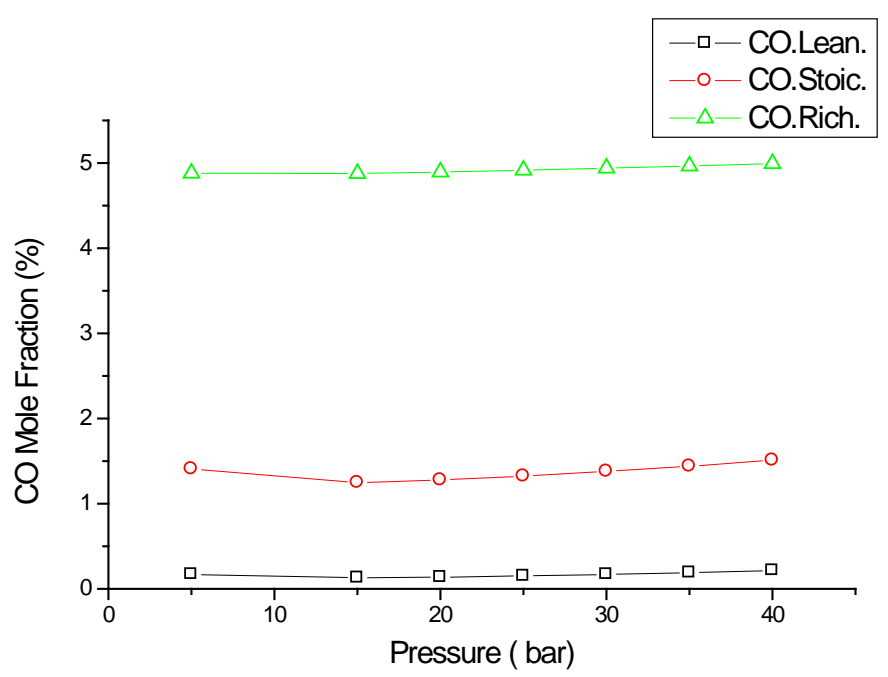

Figure 1. CO Emissions Mole Fraction (\%) For Methane Mixtures $(\phi=0.8$, $\phi=1.0$ and $\phi=1.2)$ at initial Pressure and Temperature, $P_{o}, T_{o}$ Ranging (5 40) bar and $(350-650) \mathrm{K}$.

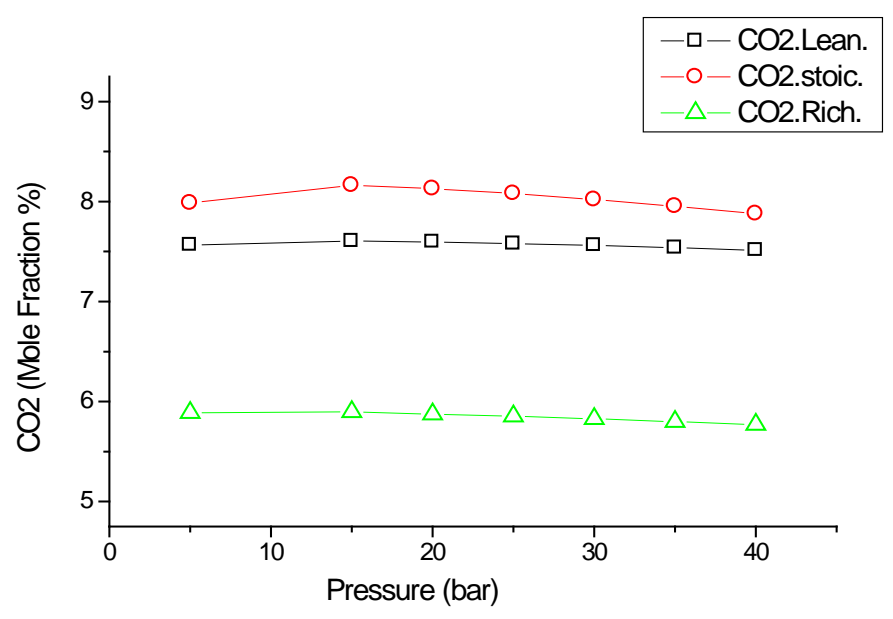

Figure 2. $\mathrm{CO}_{2}$ Emissions Mole Fraction (\%) For Methane Mixtures ( $\phi=0.8$, $\phi=1.0$ and $\phi=1.2)$ at initial Pressure and Temperature, $P_{o}, T_{o}$ Ranging (5 40) bar and $(350-650) \mathrm{K}$.

also showed that for all three mixtures, NO emissions increases with increased pressure and temperature for all three mixtures.

Finally, heat of combustion $(\mathrm{Q} \mathrm{kJ} / \mathrm{kg}$ ) was calculated for every mixture at all pressures and temperatures. The results were plotted in Figure 4. It was clear that rich mixtures of methane produced the highest values of combustion heat, $\mathrm{Q}$, where minimum value was found to be for lean mixtures. Results also showed that fairly sharp increase in $\mathrm{Q}$ values as pressure and temperature increase for all three mixtures. An important fact that must be considered when conducting 


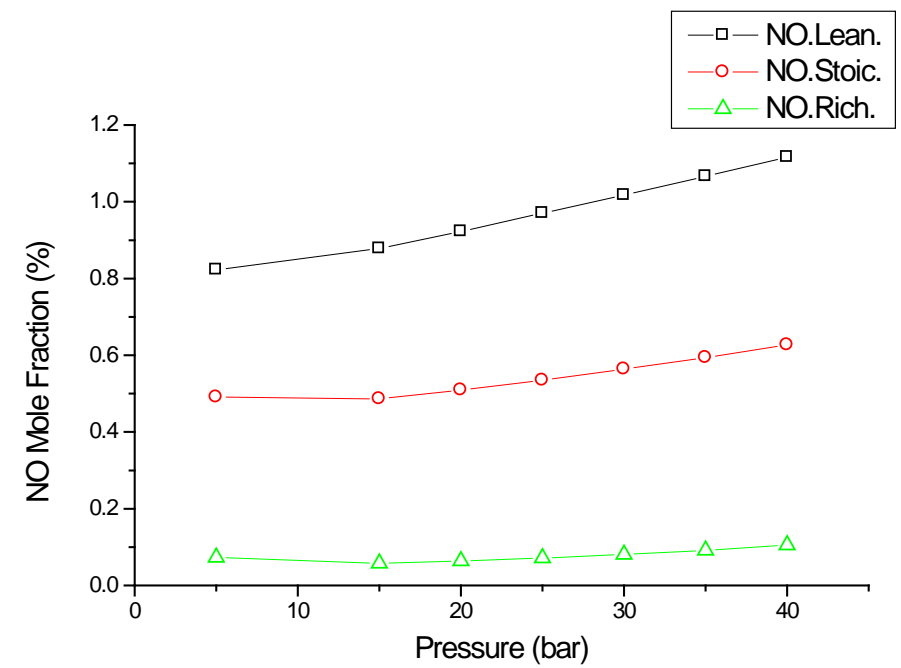

Figure 3. NO Emissions Mole Fraction (\%) For Methane Mixtures ( $\phi=0.8$, $\phi=1.0$ and $\phi=1.2)$ at initial Pressure and Temperature, $P_{o}, T_{o}$ Ranging (5 $40)$ bar and $(350-650) \mathrm{K}$.

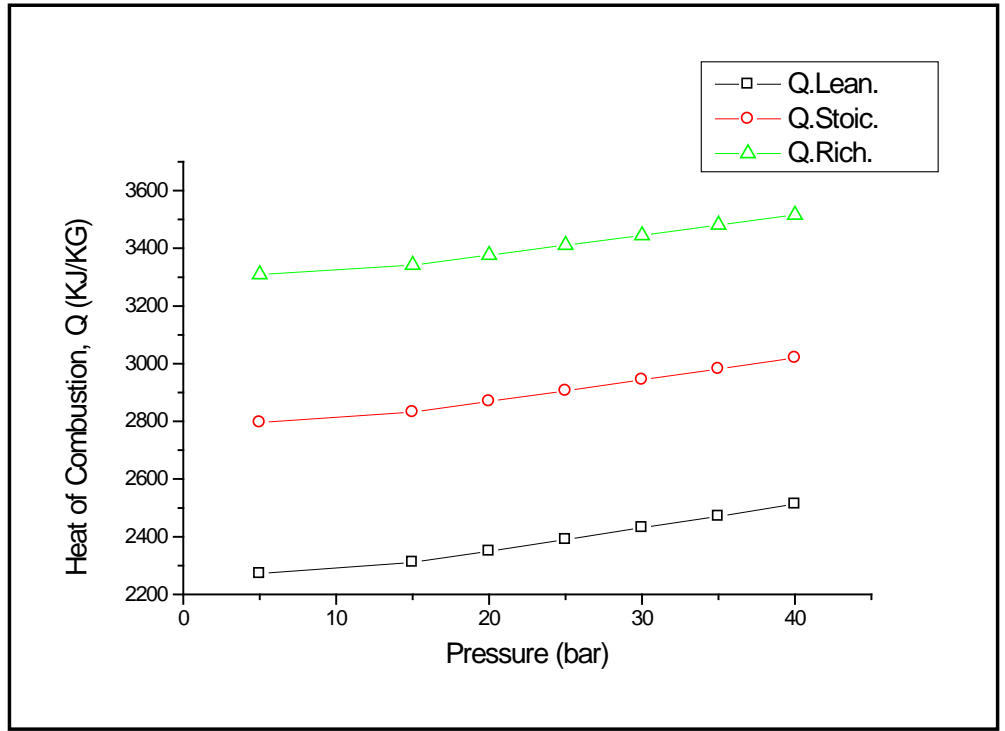

Figure 4. Heat of Combustion, $Q$, For Methane Mixtures $(\phi=0.8, \phi=1.0$ and $\phi=1.2)$ at initial Pressure and Temperature, $P_{o}, T_{o}$ Ranging (5 - 40) bar and $(350-650) \mathrm{K}$.

further studies of such emissions production rates, are flame structure and chemical reactions mechanisms which may affect the overall concentrations of $\mathrm{CO}_{\mathrm{x}}$ and $\mathrm{NO}_{\mathrm{x}}$.

\section{Conclusion}

This paper starts with briefs for effects of elevated pressures and temperatures (such those in engines) on production rates of emissions which is a major con- 
cern nowadays. Methane fuel was used in this study with different equivalence ratios, lean, stoic metric and rich mixtures $(\phi=0.8,1.0,1.2)$ at different values of pressures and temperatures similar to those in engines to investigate the effects of these parameters on $\mathrm{No}, \mathrm{Co}_{\mathrm{x}}$ emissions production rates as a mole fraction. In this paper, in-house software was used to evaluate emissions produced from methane fuel. These emissions include $\mathrm{CO}, \mathrm{CO}_{2}$, and $\mathrm{NO}$ for three different equivalence ratios, lean, $(\phi=0.8)$, stoichiometric, $(\phi=1.0)$, and rich, $(\phi=1.2)$ and mixtures at different pressures and temperatures. It was quite evident from the outcomes of this study that concentrations of methane fuel $(\phi)$ for the three mixtures have strong influences on the amount of produced emissions at the end of each combustion process. It was also found that it has strong influences on the amount of combustion heat $(Q)$, for each mixture. This leads to an important fact to be considered when designing engines combustion chamber sand in selecting type of fuel in order to minimize pollutants emissions produced by such engine.

\section{References}

[1] Glassman, I. (1988) Combustion. Academic Press, Orlando, Florida.

[2] Abian, M., Peribanez, E., Millera, A., Bilbao, R. and Alzueta, M.A.U. (2013) Synergy between Nitrogen Oxides and Soot Precursors: Influence on Pollutants Emissions. Proceedings of the European Combustion Meeting.

[3] Heck, R. and Farrauto, R. (2001) Automobile Exhaust Catalysts. Applied Catalysis A: General, 221, 443-457. https://doi.org/10.1016/S0926-860X(01)00818-3

[4] Lox, E.S.J. (2008) Handbook of Heterogeneous Catalysis. Wiley-VCH Verlag GmbH \& Co, Weinheim.

[5] Hochgreb, S. (2014) On Mixing and Shaking: Structure and Dynamics of Turbulent Stratified Flames. University of Cambridge, Cambridge.

[6] Galarbog, P.G., Alzuueta, M.U., Dam Johansen, K. and Miller, J.A. (1998) Combust. Flame, 115, 1-27. https://doi.org/10.1016/S0010-2180(97)00359-3

[7] Roy, M.M., Tomita, E., Kawahara, N., Harada, Y. and Sakane, A. (2009) International Journal of Hydrogen Energy, 34, 7811-7822.

[8] Heywood, J. (1988) Internal Combustion Engines Fundamentals. McGraw-Hill Book Company, New York.

[9] Papagiannakis, R.G., Rakopoulos, C.D., Hountalas, D.T. and Rakopoulos, D.C. (2010) Emission Characteristics of High Speed, Dual Fuel, Compression Ignition Engine Operating in a Wide Range of Natural Gas/Diesel Fuel Proportions. Fuel, 89, 1397-1406. https://doi.org/10.1016/j.fuel.2009.11.001

[10] Griffith, D.W.T., Bryant, G.R., Hsu, D. and Reisinger, A.R. (2008) Methane Emissions from Free-Ranging Cattle: Comparison of Tracer and Integrated Horizontal Flux Techniques. Journal of Environmental Quality, 37, 582-591. https://doi.org/10.2134/jeq2006.0426 